\title{
EL REBUSQUE, UNA ESTRATEGIA DE INTEGRACIÓN SOCIAL de los migrantes colombianos en Francia
}

\author{
Olga L. GonZÁlez \\ Investigadora asociada del Cidse, Universidad del Valle, Cali, Colombia \\ olgalu@free.fr
}

\begin{abstract}
Resumen
[Ste artículo examina las acciones de los migrantes colombianos en París para obtener [sus derechos sociales. Estas se clasifican en dos ejes: el primero, habitual en la sociología, que las discrimina en individuales o colectivas. El segundo, propuesto por la autora, las ordena según obedezcan a estrategias de rebusque o de reivindicación. De la observación empírica se evidencia la tendencia de los migrantes colombianos hacia las acciones de rebusque individual, situación que contrasta con la de otros colectivos nacionales. El artículo desarrolla la noción de rebusque y la propone como filtro de lectura para descifrar otro tipo de acciones.

PALABRAS CLAVE: rebusque, migrantes colombianos, París, derechos sociales, acción colectiva, sociología de la acción.
\end{abstract}

\section{REBUSQUE, A STRATEGY OF SOCIAL INTEGRATION By Colombian immigrants in France}

\begin{abstract}
THIS ARTICLE EXAMINES THE ACTIONS OF COLOMBIAN MIGRANTS IN PARIS IN THEIR ATTEMPTS TO OBTAIN social rights. The actions are classified under two axis: the first one, common in sociology, discriminates these actions as individual or collective. The second one, proposed by the author, organizes them according to strategies of rebusque or vindication. Empirical observation evidences a tendency of Colombian migrants towards indivual rebusque strategies. This situation contrasts with other national collectivities. The article develops the notion of rebusque and proposes it as a stimulating lense to decipher other types of actions.

KEY WORDS: rebusque, Colombian migrants, Paris, social rights, collective action, action sociology.
\end{abstract}

\section{Revista Colombiana de Antropología}

Volumen 44 (2), julio-diciembre 2008, pp. 25I-279 


\section{INTRODUCCIÓN}

OS DERECHOS SOCIALES SON UNO DE LOS PILARES DE LA SOCIEDAD INDUStrial; obtenidos al final del siglo diecinueve y afianzados en las Ldécadas posteriores a la segunda guerra mundial, completan el repertorio de los derechos y las libertades clásicos y son uno de los fundamentos del estado de bienestar de los países del Norte. En este artículo analizo la acción de migrantes colombianos para acceder a esos derechos, migrantes que provienen de una sociedad en donde su nivel de cumplimiento es bajo y que llegan a residir en un país en donde su desarrollo es amplio. Me apoyo en los hallazgos del trabajo de campo así como en una bibliografía calificada sobre procesos de integración social y legal.

El artículo está dividido en cuatro secciones. En la primera caracterizo las formas de organización de los migrantes colombianos en Francia según el eje tradicional acción individual-acción colectiva. En la segunda sección postulo que el eje individual-colectivo es incompleto para dar cuenta de los fenómenos observados. Introduzco la noción de rebusque, que opongo a la de reivindicación, y que se refiere a las estrategias de los actores. Las dos secciones siguientes amplían e ilustran el nuevo eje: en la tercera presento una síntesis de la acción y muestro que el rebusque es un tipo de acción frecuente entre los migrantes provenientes de la región andina. Contrasto sus estrategias para adquirir documentos legales y derechos sociales con las que llevan a cabo migrantes provenientes de otras naciones y culturas. En la cuarta y última parte amplío el espectro de la estrategia del rebusque y muestro que esta noción es operativa.

\section{SOCIOLOGÍA DE LA ACCIÓN Y MIGRANTES}

$\gamma^{\mathrm{l}}$ ENERALMENTE, EN LOS TRABAJOS SOCIOLÓGICOS SOBRE LA INTEGRACIÓN DE la población migrante se suele adoptar el marco de referencia de la sociedad de acogida (Dewitte, I999). Aun cuando útil, este enfoque tiene un límite evidente: privilegia un solo punto de vista. En este artículo mostraré que el campo de estudio de las migraciones se presta también para reflexionar partiendo del punto de vista del migrante, y que este ángulo enriquece la teoría de la acción. El trabajo interroga prácticas ordinarias de los migrantes 
colombianos en Francia; en concreto, las acciones que ellos -cuyos rasgos principales y sus diferencias con otros migrantes he descrito en González, 2007- desarrollan con miras a lograr su integración legal y social. Parto de la idea según la cual los "hechos sociales" deben ser tratados como cosas (Durkheim, 1967). Nuestros "hechos sociales" serán las acciones que desarrollan los migrantes para obtener los documentos legales y los derechos sociales, principalmente en materia de salud y trabajo.

El texto se apoya en un trabajo de campo efectuado en la región parisina entre 2003 y 2006, lapso durante el que hice observación etnográfica y entrevistas semidirigidas con migrantes provenientes de tres países andinos (Colombia, Ecuador y Perú), quienes fueron interrogados en medios diferentes: algunos en entornos asociativos, otros en sitios de reunión -tiendas y restaurantes- o durante ocasiones festivas como los torneos de fútbol. Busqué entrevistar a líderes comunitarios o miembros de asociaciones y a personas sin vínculos con organización alguna. Así mismo, elaboré un cuestionario con preguntas específicas sobre el conocimiento que tienen los migrantes acerca de los derechos sociales, de las instituciones francesas que trabajan por sus derechos sociales y sobre la utilización de esas instituciones. El cuestionario fue completado con cuarenta personas. El trabajo incluyó también la consulta y el escrutinio de los informes de gestión de las instituciones francesas de atención al migrante, entrevistas con algunos de sus miembros y pasantías en dos centros de atención al migrante hispanohablante. Vale anotar que en este artículo me concentraré en los hallazgos relativos a los colombianos.

\section{El eje acción colectiva-acción individual}

EL PRIMER CRITERIO QUE PERMITIRÁ CLASIFICAR LOS HECHOS SOCIALES SERÁ EL vector "acción individual” o "acción colectiva”. La primera es la que lleva a cabo el sujeto, tomado individualmente o en su ámbito familiar más cercano, para obtener sus derechos sociales. Paralelamente, postulo que la acción colectiva es la que busca obtener resultados para varios individuos, más allá del marco personal o familiar. El gráfico I muestra cómo se traduce este eje. 
EJE ACCIÓN INDIVIDUAL-ACCIÓN COLECTIVA

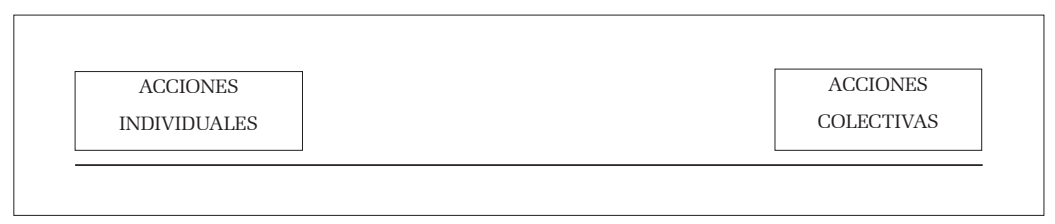

Los hallazgos del trabajo de campo indican que la mayoría de los migrantes colombianos lleva a cabo acciones de tipo individual para informarse y obtener sus derechos sociales y sus documentos. Los dos ejemplos siguientes son paradigmáticos de las situaciones que se presentan:

Jorge es un colombiano que llegó a París en 1998 y que ha intentado por todos los medios regularizar su situación. En el plano jurídico ha multiplicado las gestiones para obtener sus papeles. Actualmente tiene dos recursos: solicitó el asilo e introdujo un dossier alegando que es padre de una niña nacida en Francia. Él cree que alguno de esos procedimientos "reventará".

Jaime, colombiano también, llegó a Francia en junio de I998. Tiene la Ayuda médica del estado (AME) desde i999. Un compatriota le dijo adónde ir y le explicó el trámite. Llevó los papeles que le pedían y se la dieron rápidamente.

LA PROTECCIÓN SOCIAL DE LOS MIGRANTES EN FRANCIA

Los extranjeros y los franceses están cobijados por el mismo régimen de protección social, a condición de residir legalmente. Mientras las personas de escasos recursos tienen derecho a la Cobertura médica universal (CMU), los migrantes en situación irregular a la Ayuda médica del estado (AME). La CMU depende financieramente del régimen contributivo y la AME de la solidaridad: es una ayuda del estado financiada con impuestos. Según lo dispuesto por la ley, a estos derechos se accede mediante un trámite sencillo en las cajas de protección social.

En ambos casos, el individuo busca solucionar problemas para sí o para su entorno inmediato; sus acciones no cubren la esfera de individuos más allá de su núcleo familiar estrecho. En contraste, son poco frecuentes las situaciones en las que se encuentran formas de acción colectiva. Uno de estos raros casos lo representan los santuareños, una comunidad muy cohesionada: 
Santuario, una comunidad de la región parisina. Santuario es un municipio cafetero de 25.000 habitantes situado en el departamento de Risaralda (Colombia). Un número considerable de sus nativos reside en el exterior, principalmente en Estados Unidos, Inglaterra y Francia. En la región parisina viven, según los santuareños de más antigüedad, alrededor de quinientas personas. Los primeros llegaron en la década de 1980. Las familias se fueron completando; luego llegaron los amigos, después las familias de los amigos, y así sucesivamente. Laboralmente, en el caso de Santuario se dio un proceso de "cadena migratoria” (Pardo, I995), con redes de apoyo amplias, que cobijaban a familias extensas y a otros coterráneos (Rea, 2005). En esta comunidad los lazos sociales se refuerzan periódicamente, por ejemplo, mediante las fiestas y los eventos deportivos, ocasiones en las que se actualizan noticias, se presenta a los recién llegados y se renuevan las relaciones. Varios miembros de Santuario han obtenido el asilo gracias a la ayuda de sus paisanos, que les indican cómo llenar los formularios y cómo construir los relatos que examinará el organismo encargado de decidir las atribuciones -la facilitación de "pruebas" y la coherencia del relato se convierten en un arte cuyas reglas deben conocer los aspirantes al refugio-. Muchos acceden al trabajo por medio de las empresas de construcción de los santuareños más antiguos. Así mismo, gracias a la comunidad obtienen la información sobre la protección social, el alojamiento y la instalación.

Otro caso que seguí de cerca y que responde a una acción colectiva es el relativo a una familia colombiana que describo a continuación. Conviene anotar que durante el trabajo de campo observé este tipo de acciones muy excepcionalmente entre colombianos, siendo más frecuente en otras comunidades nacionales.

La familia Pérez (Pedro y Ana, padres, y René y Pablo, hijos) lleva cinco años viviendo en Francia. Todos nacieron en Cali, donde él trabajaba como transportador de valores. Les iba "bien", tenían "casa propia". Pero en 2000 Pedro fue atracado. "Me sacaron un arma". La pareja decidió que a la primera oportunidad se iría a otro país.

La familia de Ana tenía familiares en Francia, España y Estados Unidos. Después de hacer algunas llamadas el viaje se concretó y el destino resultó ser Francia. Tan pronto llegaron, comenzaron a trabajar, Pedro como obrero -en el sector de la construcción de grandes obras- y Ana como empleada doméstica. Ninguno tenía papeles. Actualmente, los Pérez viven en un apartamento de treinta y cinco metros cuadrados en París y llevan una vida ordinaria. Los niños van al colegio; el mayor saca buenas notas, que incluso le otorgaron un diploma de felicitación del alcalde de París. Por fuera de los gastos diarios, logran ahorrar cerca de mil euros mensuales. Piensan regresar a Colombia en el futuro. 
A fines de 2005, los Pérez vivieron momentos de zozobra en Francia. Los hechos se precipitaron a partir de la detención de Pedro, durante un control policial. Lo amenazaron con expulsarlo a él y a su familia en un lapso muy breve. Entonces Ana se puso en contacto con dos asociaciones que le indicaron en el consulado de Colombia, que ella conocía bien, pues ocasionalmente había trabajado allí como aseadora. Aun cuando piensa que esas llamadas "no sirvieron para nada" -quizá porque no le dieron una respuesta inmediata-, la información comenzó a circular por internet. Por este canal llegó a la Red de Educación sin Fronteras, que divulgó los nombres completos de la familia y el nombre del colegio donde asisten los niños.

Elisabeth, documentalista francesa suscrita a la lista de correo electrónico de la Red de Educación sin Fronteras, vio que en ese mensaje aparecía el nombre del colegio de su hijo. Averiguó un poco más y se dio cuenta de que René, el hijo mayor de los Pérez, era compañero de clase de su propio hijo. Tomó entonces esta causa como propia. Organizó reuniones en el colegio, alertó a los profesores, solicitó la ayuda de los padres de familia y de los vecinos del barrio. En pocos días se creó un Comité de apoyo a la familia Pérez. El Comité organizó marchas, se puso en contacto con la prensa y la televisión y logró el apoyo de algunos diputados, ediles, concejales y magistrados. Presionó para obtener la anulación de los procedimientos de expulsión y abogó por la regularización. Al cabo de unos cuatro meses de incertidumbre y luchas jurídicas y políticas, las autoridades regularizaron la situación de la familia Pérez.

\section{RED DE EDUCACIÓN SIN FRONTERAS}

La Red de educación sin fronteras (Resf) tomó forma en 2004. La iniciativa federa a los educadores, padres de familia, individuos, sindicatos, asociaciones de la sociedad civil y organizaciones políticas que, invocando los derechos del hombre, ven con preocupación la forma como se procede a la exclusión de extranjeros -y especialmente de niños y jóvenes en edad escolar y universitaria- que no poseen sus permisos de estadía legal en Francia. La Resf funciona como una red de apoyo, divulgación de información y acciones encaminadas a luchar contra las expulsiones.

Estas dos acciones involucran a colectivos que van más allá del individuo o de su familia nuclear. La acción colectiva de los santuareños con respecto a sus derechos sociales reposa en los lazos regionales informales, mientras que la acción colectiva alrededor de la familia Pérez se cristaliza en una movilización de tipo militante. Acorde con el eje acción individual/acción colectiva, se obtuvo el gráfico 2. 


\section{GRÁFICO 2}

ACCIONES INDIVIDUALES Y COLECTIVAS PARA ACCEDER A LOS DERECHOS SOCIALES

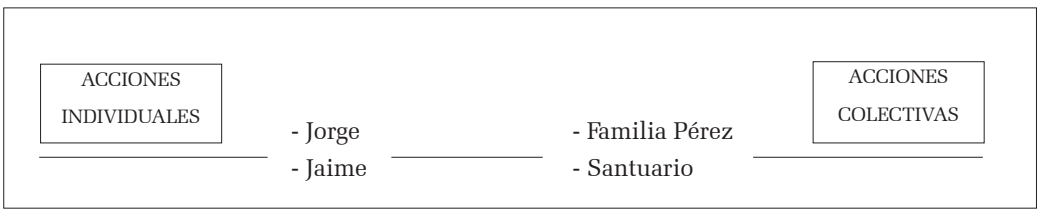

Podría seguir agregando casos a lo largo de este eje o clasificar las acciones según el grado en que correspondan a los criterios "más colectivo" o "más individual". Sin embargo, establecer una jerarquía de este tipo no es el propósito de este artículo. Aun cuando brinda un primer nivel de interpretación en cuanto a las características de la acción, este eje no aporta una dimensión explicativa adicional. Otra posibilidad, que parece más enriquecedora, es introducir un nuevo eje, que propongo en la siguiente sección.

\section{REBUSQUE/REIVINDICACIÓN: UN EJE ESCLARECEDOR}

ऍL EJE REBUSQUE/REIVINDICACIÓN PERMITIRÁ COMPLETAR LOS TIPOS DE -acción. Se refiere a las estrategias que motivan al actor, que - pueden ser conscientes o no. El individuo las interioriza y las despliega en su práctica. Considero que el actor puede desplegar dos tipos de estrategias para obtener sus derechos sociales: la reivindicación y el rebusque, que explico e ilustro a continuación.

\section{La reivindicación}

SEGÚN EL DiCCIONARIO DE LA REAL ACADEMIA ESPAÑOLA, LA REIVINDICACIÓN es la acción de "reclamar algo a lo que se cree tener derecho". También es "reclamar o recuperar alguien lo que por razón de dominio, cuasi dominio u otro motivo le pertenece". Estas definiciones la asimilan al reclamo, siempre y cuando sea un reclamo fundado: sólo se reivindica aquello que se considera legítimo. De 
manera extensiva, diré que la reivindicación es empleada como sinónimo de exigencia.

En los párrafos que siguen emplearé la noción en un sentido preciso: considero que la reivindicación es el comportamiento subjetivo del individuo que, considerando o sabiendo que existen derechos, intenta que los principios se cumplan y traduzcan en la práctica. En suma, la reivindicación cubre todo el proceso de gestiones que suponen la obtención de un derecho.

Evidentemente, supone el conocimiento previo de los derechos, o cuando menos la idea de que estos se pueden activar u obtener de alguna manera. Se trata de un tipo de estrategia muy frecuente en Francia: las huelgas, las marchas y manifestaciones, así como los reclamos individuales y las quejas para exigir el cumplimiento de derechos existentes o para pedir el reconocimiento de nuevos derechos, hacen parte del repertorio usual en esta sociedad. A manera de ilustración, un dato significativo: en Francia, en la década de I990 hubo cerca de ocho mil manifestaciones al año, es decir un promedio de veinte al día (Fillieule, I993).

Ahora bien, aun cuando el contexto nacional sea propicio para la reivindicación, no necesariamente resulta siendo incorporado por los diferentes colectivos de migrantes. Las conclusiones de un informe de Médecins du Monde (Fahet et al., 2004) muestran que, a derechos teóricos similares, en la práctica los franceses pueden ejercer sus derechos relativos a la protección social el doble de veces que los extranjeros. De hecho, no basta con residir en Francia para adoptar la estrategia de la reivindicación. Las organizaciones y asociaciones que trabajan con los extranjeros conocen muy bien este tipo de problemas. Muchas de ellas llevan a cabo acciones para revertir la tendencia y exigir el cumplimiento de la ley. Es el caso del Groupe d'information et de soutien des inmigrés (Gisti), que lucha por la defensa de los derechos de los extranjeros:

Aún hoy, los objetivos de la asociación, Grupo de Información y Apoyo a los Trabajadores Migrantes (Gisti) [su sigla en francés], siguen siendo los que se definieron al momento de su creación. Se trabaja en torno a dos líneas principales: una actividad de información jurídica destinada a los migrantes y las asociaciones que los ayudan y una actividad de apoyo jurídico, y también política, con las luchas que llevan a cabo los migrantes en Francia (Marek, 2002). 
Las organizaciones que trabajan en el sentido de la reivindicación pueden tener como meta también lograr nuevos derechos. Así sucede, por ejemplo, con la red de apoyo Éducation sans frontières: los padres de familia, junto con sindicatos $\mathrm{y}$ asociaciones de defensa de los derechos humanos, forman una red para apoyar a los niños y jóvenes irregulares amenazados de expulsión y ejercen presión sobre las autoridades para cambiar las leyes en un sentido favorable a los migrantes (véase el recuadro de la p. 256).

En estos dos casos se trata de organizaciones creadas y animadas por franceses que trabajan con y por los extranjeros. Pero existen también colectivos y asociaciones compuestos exclusiva o mayoritariamente por extranjeros y migrantes, como sucede con el $9^{\text {ème }}$ Collectif des Sans-Papiers (o colectivo de los "sin papeles" de la región parisina):

\begin{abstract}
Al movilizarnos en el colectivo número 9, queremos expresar nuestro rechazo a seguir viviendo escondidos, clandestinos, humillados. Somos hombres y mujeres determinados a luchar por adquirir nuestra libertad y nuestra dignidad, pese al arsenal represivo impuesto por los diferentes gobiernos (de derecha y de izquierda). El colectivo se sitúa en la perspectiva de lucha a largo plazo, y tiene como objetivo la regularización de todos los sin papeles ${ }^{1}$.
\end{abstract}

Entre los migrantes colombianos, el caso de la familia Pérez responde claramente a una estrategia de reivindicación. Sin el apoyo del Comité, lo más probable es que ellos hubieran perdido ese combate legal. Esto es especialmente cierto si se tiene en cuenta el contexto político francés de 2006, año en que se endurecieron las leyes migratorias y aumentó el

I. Presentación del Collectif par le gème collectif, publicada el ro de noviembre de 2004. http://pajol.eu.org/article685.html. Consultado en internet el 3 de abril de 2006. número de expulsiones.

Paralela a esta experiencia, la reivindicación también se da en situaciones más corrientes. El caso de Jaime reseñado antes -el migrante irregular que gestiona su Ayuda médica del estado- entra en esta categoría. Otro intento de reivindicación de los migrantes colombianos es el de la asociación Comfra, Comunidad colombiana en Francia, que refiero a continuación: 
Comfra fue un intento de organización colectiva de migrantes colombianos con hijos nacidos en Francia. Este colectivo nació como resultado de un enfrentamiento con el consulado colombiano. La historia se origina en el cambio de una disposición legal: en la época en que hice las primeras encuestas, antes de 2002, los hijos de colombianos nacidos en Francia podían ser franceses. Hasta entonces, muchos padres de niños nacidos allí lograban regularizar su situación después de declarar a sus hijos ante las autoridades francesas.

A principios de 2002, una ley aprobada en Colombia dispuso que los niños podían optar por la nacionalidad colombiana si sus padres los declaraban en el consulado al nacer. Por esta razón, después de esa fecha muchos migrantes colombianos evitaron declarar a sus hijos ante las autoridades colombianas en Francia y siguieron tramitando los papeles de identidad con las autoridades francesas competentes. Esperaban, de esta manera, regularizar su situación.

En ese contexto, el consulado de Colombia comenzó a emitir circulares en las que se afirmaba que era "obligatorio" declarar a los hijos en el consulado. Para muchos padres colombianos de hijos nacidos en Francia esto era un abuso de poder. Consideraban que se lesionaban sus derechos y que se entorpecían los trámites para lograr una posible regularización.

Algunas personas formaron un grupo informal e iniciaron a recolectar firmas para solicitar, mediante un derecho de petición dirigido a las autoridades colombianas, la aclaración de la norma. Para esa petición se recolectaron ciento cincuenta firmas. Simultáneamente, el grupo hacía reuniones informativas y brindaba asesoría informal a personas que necesitaban arreglar el problema de los papeles. Esta acción se concretó en la creación de la asociación Comunidad colombiana en Francia (Comfra), cuyos estatutos y objetivos fueron publicados en el Diario Oficial.

Comfra ha sido una de las pocas experiencias de acción colectiva promovidas por migrantes colombianos sin lazos regionales previos y que buscaban obtener sus derechos jurídicos y sociales. Acción notable también por el hecho de que sus promotores estaban en situación irregular, siendo que este tipo de movilización ocurre muy ocasionalmente (Siméant, I998; Mathieu, 2004). 


\section{El rebusque}

EL SEGUNDO COMPORTAMIENTO DEL ACTOR CON RESPECTO A SUS DERECHOS sociales es el que llamamos rebusque ${ }^{2}$. El rebusque se refiere a cierto tipo de relación entre el individuo y la ley, y de manera más general, a cierto tipo de relación entre el individuo y las instituciones. En la estrategia del

2. En lenguaje colombiano, el rebusque se refiere a los mecanismos económicos y sociales que se producen en la esfera informal. En nuestra óptica, el rebusque traduce unos comportamientos sociales específicos. rebusque, el individuo se sitúa por fuera de la esfera del derecho y posee una noción débil de sus deberes. Paralelamente, tiene poca conciencia de sus derechos o no espera mayor cosa de ellos. En esta lógica, el individuo emplea mecanismos distintos a acudir a la ley o concibe esta en una dimensión utilitarista o mágica. Algunos ejemplos permiten explicitar esta acepción del rebusque:

Hugo, colombiano de veinticuatro años de edad, llegó a Francia hace tres años y está en situación irregular. Vive en casa de su hermano y de su nuera. No conoce el sistema de ayudas sociales a las que tendría derecho. No ha oído hablar nunca de la Ayuda médica del estado ni conoce la palabra allocation [es decir, los subsidios sociales].

En raras ocasiones vi individuos tan desligados de la esfera institucional relativa a la protección social. En el caso que cito, el hermano y su familia mantenían deliberadamente a la persona. Noté con mayor frecuencia que el rebusque aparece cuando el individuo no concibe el derecho como el fundamento legítimo de su pedido, sino como un recurso entre varios posibles.

El primer caso citado es emblemático: para Jorge prima la idea de que alguna de las variantes puede funcionar; por eso las ensaya todas. Sin embargo, desde el punto de vista jurídico, esta combinación de varios procedimientos puede ser perjudicial porque las diferentes demandas son incompatibles entre sí. En el transcurso del trabajo de campo, pude observar que este punto es origen de malentendidos entre los comités de apoyo a los "sin papeles" y algunos migrantes colombianos que entran en contacto con ellos. Los abogados de las asociaciones alegan que no tienen la certeza de conocer todas las variables para hacer su trabajo con criterio profesional. Los migrantes, por su parte, usan todos los dispositivos a su alcance. 
En la estrategia del rebusque el individuo emplea métodos que no tienen en cuenta la existencia del derecho o concibe la ley en una perspectiva utilitarista. Esto no impide, por cierto, que el derecho sea uno de los recursos que utilice, como sucede con Raúl:

\begin{abstract}
Raúl también es colombiano. Como periodista hizo parte del gabinete del alcalde de una gran ciudad, y debió salir de manera precipitada del país después de recibir amenazas de muerte. Compró un tiquete aéreo por medio de una agencia turística y se inscribió en una excursión para obtener la visa. Su idea era llegar a España, donde vive un familiar. Sin embargo, su punto de ingreso a Europa fue Francia. “Tan pronto pude, me escapé de la excursión”. Raúl viajó a España, pero rápidamente lo reenviaron a Francia, pues según las convenciones internacionales el asilo se debe solicitar en el país de Europa al que se llega. En Francia, sin contactos ni dinero, está a punto de dormir en la calle. Él no sabe cuáles son los trámites para solicitar el asilo.
\end{abstract}

En este caso, el actor ignora los procedimientos legales para efectuar su demanda, aunque desde Colombia tenía en mente solicitar el asilo. Esta figura le parecía muy vaga: el individuo veía el final del túnel pero no sabía que antes debía recorrerlo. Invocaba el derecho en un sentido mágico, y no como un mecanismo que requiere formulaciones, tiempos y procedimientos.

El rebusque puede surgir como último recurso ante el bloqueo de una situación. En este caso, la estrategia corresponde a una acepción corriente de la palabra rebusque, es decir como sinónimo de atajo, camino no convencional para obtener un fin, ingenio en la solución de un problema. Cuando la administración bloquea el acceso a un derecho o interpone obstáculos considerados extravagantes, el individuo opta concientemente por el rebusque:

Vanesa es de Cali, tiene cuarenta y cinco años y reside en Francia desde hace cinco años con sus dos hijos y su nieto. En 2003 buscaba información sobre la manera de obtener la regularización. Le aconsejé ir adonde los asistentes sociales de la alcaldía y acudir al Comité de apoyo de los "sin papeles" de su ciudad. Allí estuvo, pero en términos corteses la desanimaron: dado su historial, no tenía posibilidades de obtener los papeles por el momento. Al cabo de unos meses tuvo problemas para obtener su Ayuda médica del estado, aunque cumplía los requisitos para tenerla. Contactó de nuevo al 


\begin{abstract}
Comité y comenzó un largo periplo: redacción de cartas, citas, un rechazo, más cartas explicativas, adjuntar documentos, cita en el tribunal con un miembro del Comité, nuevo rechazo. A Vanesa le parecía que había perdido mucho tiempo con el Comité. Decidió no seguir con los procedimientos legales para exigir su AME, sino acudir a otro sistema: le pidió a un conocido, domiciliado en París, que le hiciera una atestación falsa. Sabía por rumores que en París otorgan más rápido la AME. Al final, por este canal recibió una respuesta positiva y obtuvo la prolongación de su AME por un año.
\end{abstract}

Este ejemplo ilustra dos hechos: primero, la dificultad creciente que tienen las personas para obtener sus derechos legalmente, algo que anoté cuando dije que a derechos teóricos similares, en la práctica los franceses ejercen sus derechos el doble de veces que los extranjeros. Las ciencias sociales francesas estudian la incoherencia entre los principios y la práctica de acuerdo con el enfoque de la " falta de funcionamientos", que ha tenido un gran desarrollo (Fassin, 2002).

Segundo: que las estrategias de rebusque y reinvidicación pueden surgir como resultado de un cambio del entorno. Esto significa que los individuos no están condicionados a asumir determinado comportamiento. Su acción es el fruto de un entorno, pero sobre todo de un aprendizaje social previo. En el caso de los colombianos, es posible constatar la prevalencia de la estrategia de rebusque para acceder a los derechos sociales y legales.

\title{
CONSECUENCIAS
}

DE LA ESTRATEGIA DEL REBUSQUE

ก ADO EL ENFOQUE UTILITARISTA DEL REBUSQUE LOS RESULTADOS NO SE estimarán con el criterio del derecho. Por tanto, las categorías de lo justo y lo injusto, lo legal y lo ilegal no se usarán. Se preferirá medir los resultados en términos de ganancia, beneficio o pérdida.

Este hecho explica algunos comportamientos observados con frecuencia. Así, por ejemplo, quienes obtenían información sobre la manera de acceder gratuitamente a ciertos servicios médicos no la divulgaban, necesariamente, a su alrededor, y menos aún por fuera de la órbita familiar. Los individuos pensaban que esto podría afectar sus intereses y que perderían lo que con esfuerzo 
habían ganado. De la misma forma, quienes pese a las disposiciones del consulado después de 2002 obtenían la regularización gracias a que sus hijos habían nacido en Francia ${ }^{3}$, no compartían la

3. Como expliqué, según las leyes vigentes hasta 2002 los niños nacidos en Francia que no eran declarados como colombianos y que no habían vivido en Colombia tenían derecho a la nacionalidad francesa. Sus padres podían regularizarse en seguida. información con otras personas en situación similar. Aducían que si otros la obtenían sus beneficios anteriores podrían verse alterados.

Otra consecuencia directa de esta manera de concebir los derechos es el desinterés o la defección. Encontré casos de individuos que optaban por no ejercer sus derechos porque los beneficios les parecían demasiado bajos con respecto al esfuerzo para obtenerlos:

John es un colombiano que reside en situación legal en Francia desde hace veintiún años. Sobre los subsidios de alojamiento a que tenía derecho declara que nunca buscó información. Según le habían dicho: "dan muy poco".

El desinterés se manifiesta también entre individuos que concebían los subsidios como ayudas o extras y no como derechos:

Pablo es un refugiado político colombiano que reside en Francia desde hace ocho años. Acaba de tener un hijo. Conoce el completo sistema de subsidios a que tiene derecho este niño nacido en Francia. Pero él es categórico: "No quiero ayudas del estado francés". Así que no hará las gestiones para obtener los subsidios.

Algunos de los colombianos entrevistados durante este trabajo, como Pablo, concebían las ayudas sociales como ayudas o regalos. Otros esgrimían con orgullo que no necesitaban "limosnas". Para quienes actuaban de acuerdo con esta concepción las ayudas no eran vistas como "derechos" en el sentido pleno del término, sino como obras de caridad reservadas a los más pobres. Para muchos, el recorrido que los había llevado hasta donde estaban fortalecía su sentido de independencia y su desconfianza hacia las instituciones. 


\section{Hacia una nUEVA FORMULACIÓN DE LA ACCIÓN}

L CRUZAR LOS DOS EJES DE ACCIÓN INDIVIDUAL/COLECTIVA Y LAS ESTRATEgias de rebusque/reivindicación obtenemos una formulación Tde la acción más rica: donde antes había yuxtaposición de acciones ahora hay contrastes. Gráficamente, estas acciones están representadas en un plano en cuyo eje horizontal se sitúan las acciones según correspondan a la forma individual o colectiva, mientras que en el eje vertical están las que corresponden a la estrategia rebusque o reivindicación (véase el gráfico 3).

GRÁFICO 3

PlanO DE LAS ACCIONES

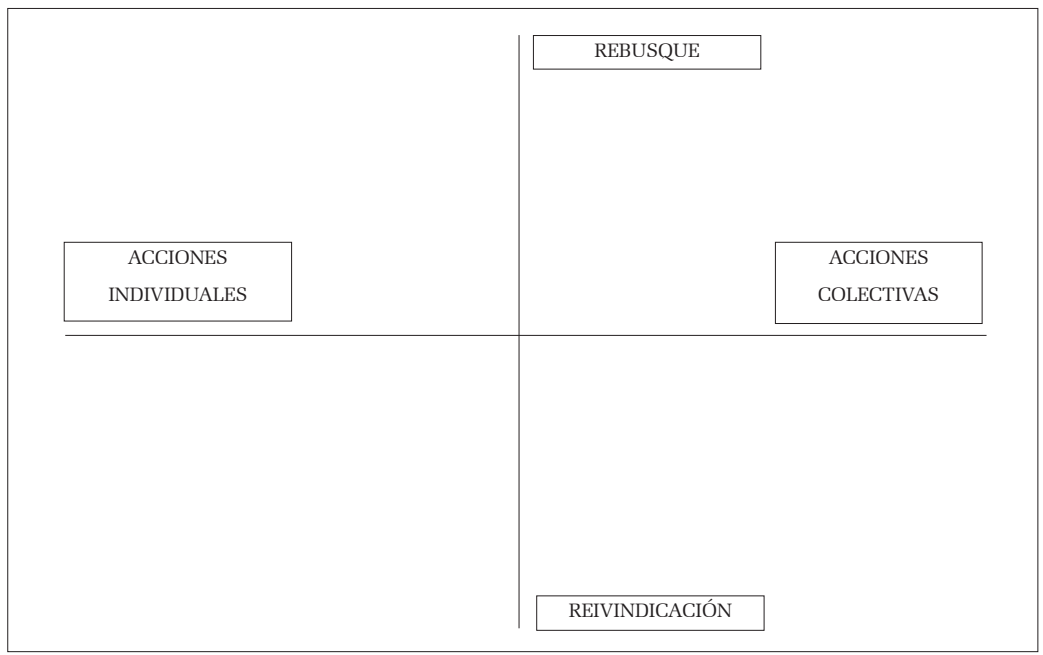

Al tomar en cuenta las motivaciones de los individuos, y no sólo la forma de la acción, esta aproximación enriquece el repertorio de acciones. Los casos que he venido presentando se aprecian en el gráfico 4, en el que se distinguen cuatro tipos de acciones: la reivindicación colectiva, la reivindicación individual, el rebusque colectivo y el rebusque individual. 


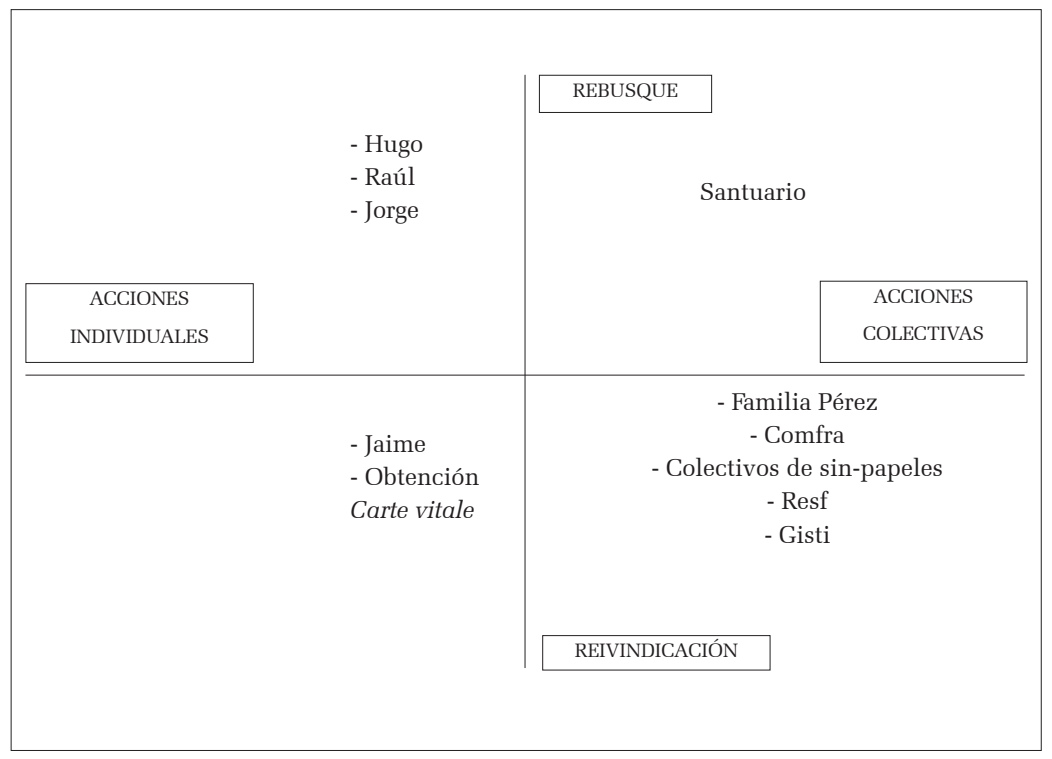

\section{Reivindicación individual}

LA MAYORÍA DE LAS GESTIONES QUE REALIZAN LOS INDIVIDUOS PARA OBTENER sus documentos y su protección social, indistintamente de si son franceses o extranjeros, corresponde a las acciones de tipo reivindicación individual, la cual se ejerce como un derecho que se tramita frente a las instituciones encargadas. No se precisa hacer presión, es un derecho reconocido y ejercido. Así es como, por ejemplo, la inmensa mayoría de los individuos adquiere su seguro médico: el trámite para obtener la carte vitale, la tarjeta electrónica que todo afiliado al seguro social tiene en Francia, es una gestión sencilla.

Los extranjeros en situación irregular también tienen derechos sociales en Francia y pueden obtenerlos por el conducto regular de la reivindicación individual. Para esto se deben cumplir dos requisitos: primero, que conozcan sus derechos; segundo, que las autoridades los acaten. En el caso de Jaime las dos premisas se cumplieron. 


\section{Reivindicación colectiva}

EN ESTE CAMPO UBICO UNA SERIE DE ORGANIZACIONES Y ASOCIACIONES CUYO trabajo gira en torno a la ayuda para la obtención de los derechos sociales. Su trabajo es eminentemente colectivo, en tanto ayudan a una población que se sitúa en un espectro amplio, más allá de la esfera individual. En los párrafos anteriores he presentado algunas de estas organizaciones: el Gisti, la red Éducation sans frontières, el Colectivo de los "sin papeles".

Otros dos casos son los de la familia Pérez y el de la asociación Comfra. En el caso de la familia Pérez, la estrategia de reivindicación fue asumida plenamente por el colectivo francés. En un primer momento, la familia colombiana estaba desconcertada: “¿Por qué hacen eso?”, se preguntaban. No concebían la solidaridad colectiva fundamentada en la reivindicación. Los miembros del colectivo, todos franceses, se ganaron su confianza progresivamente antes de efectuar las acciones ante los vecinos y la prensa.

El colectivo Comfra desplegó también una lógica de reivindicación colectiva. Cabe anotar que Comfra tuvo una existencia efímera, pese a que su líder estaba muy motivado y la asistencia a las reuniones era numerosa. Dos hechos la debilitaron profundamente: por un lado, la ley francesa de migración cambió a finales de 2003, sepultando la posibilidad de que los hijos de colombianos obtuvieran la ciudadanía francesa, y eliminando la posibilidad que tenían los padres de obtener la residencia por esa vía. Por otro, a Comfra se acercaron individuos que vieron en este colectivo una forma de lograr dinero mediante la oferta de servicios que no estaban en posibilidad de suplir profesionalmente, como la escritura de cartas, asesorías, servicio de abogado, etcétera. Con el paso del tiempo, esta iniciativa colectiva por los derechos sociales se fue desdibujando.

\section{Rebusque individual}

SEGÚN LAS ENCUESTAS EN LA REGIÓN PARISINA, EN ESTE CAMPO SE SITÚA LA mayoría de las acciones de los migrantes colombianos en situación irregular y una parte considerable de las acciones de los colombianos en situación legal. A manera de ilustración, en el gráfico 4 figuran los casos de Jorge, Raúl y Hugo, que se expusieron arriba. 


\section{Rebusque colectivo}

VimOS MÁS ARRIBA QUE LA COMUNIDAD DE SANTUARIO, ORGANIZADA COlectivamente, emplea diversas estrategias. Los nuevos miembros disponen de buena información sobre sus condiciones de instalación gracias a la red comunitaria; los más antiguos aprovechan las posibilidades brindadas por la afluencia de mano de obra de manera periódica, y los recién llegados se aseguran de disponer de trabajo desde el momento de su arribo al nuevo país.

La mayoría de las acciones de esta comunidad responde a los criterios del rebusque: predomina el intercambio informal de favores, sin mediación institucional. No se invocan las categorías del derecho sino la búsqueda de beneficios. Como señalé, el sentimiento de pertenencia común y los lazos de lealtad hacia la región cohesionan el grupo. Una consecuencia de ello es que, pese a su antigüedad, no existe ninguna asociación santuareña cuyo objetivo haya sido trabajar para y con los migrantes.

De esta caracterización sobre las formas de acceso a sus derechos sociales y legales se desprende que las acciones de reivindicación son más frecuentes entre los franceses que entre los migrantes colombianos. A cambio, estos emprenden frecuentemente acciones que corresponden al comportamiento que definí como rebusque.

Esta formulación no implica acciones estáticas o itinerarios predeterminados por otros criterios. El caso de Vanesa, cuyo recorrido se sintetiza en el gráfico 5, es ilustrativo.

Vanesa cambió de estrategia en su trasegar para obtener su afiliación al seguro médico: inició su periplo intentado una reivindicación individual, que no dio frutos. Por un conjunto de circunstancias optó enseguida por la reivindicación colectiva, pero esta lógica tampoco dio los resultados esperados. La estrategia del rebusque individual resultó ser, en último término, la forma de acción más adecuada.

\section{El REBUSQUE, UNA NOCión OPERATIVA}

$\bigsqcup^{\mathrm{p}}$ EMOS VISTO QUE EN LA ESTRATEGIA DEL REBUSQUE EL INDIVIDUO SE SITÚA por fuera de la esfera del derecho y posee una noción débil de sus deberes. Sin embargo, sería erróneo pensar que el rebusque 


\section{GRÁFICO 5}

CAmbios DE ESTRATEGIA

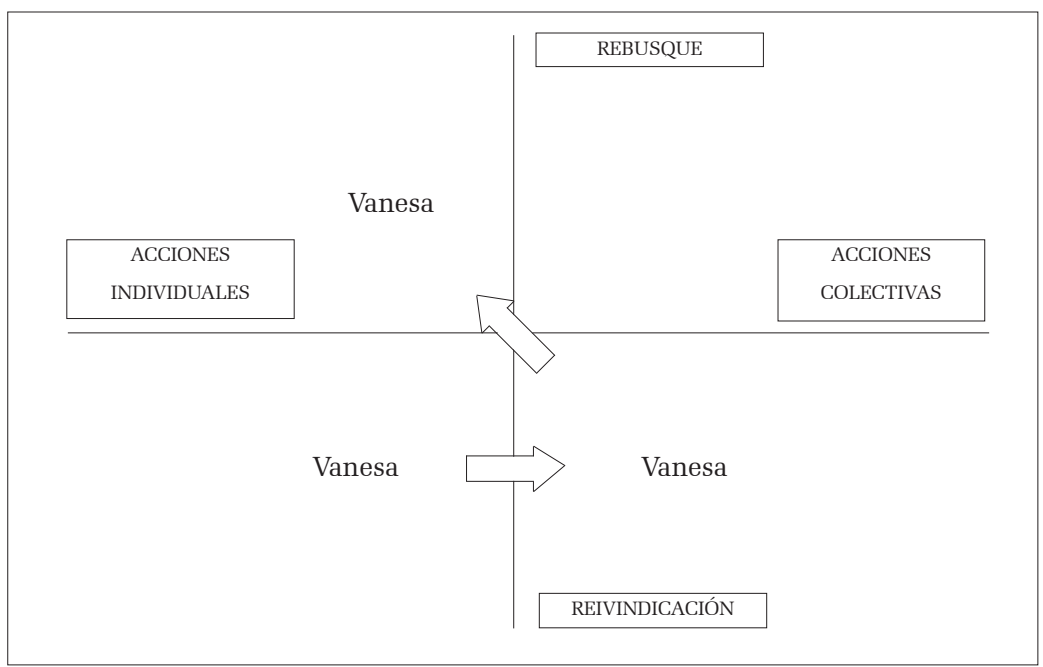

sólo tiene consecuencias en el campo de la ley. La noción de rebusque rebasa el nivel de los derechos y permite comprender comportamientos sociales más amplios. En esta sección mostraré que es una noción operativa.

\section{La mercantilización de las relaciones}

EL FILTRO QUE CONSIDERA LAS ESTRATEGIAS PARA LA OBTENCIÓN DE LOS papeles y los derechos sociales de los migrantes permite leer comportamientos sociales que, a la luz de la explicación del rebusque, adquieren una nueva dimensión. Me referiré, primero, a lo que he llamado la mercantilización de las relaciones, comportamiento que consiste en hacer intervenir transacciones de dinero en la obtención o búsqueda de los derechos sociales. Veamos dos ejemplos:

Daniel es un colombiano que lleva varios años en Francia. Quienes lo conocen lo consideran muy recursivo. Desde su llegada a ese país ha prestado sus servicios a sus compatriotas y a los migrantes de países andinos. Hace varios años facilitaba, por ejemplo, una cuenta bancaria 
para quienes no tenían dónde depositar sus cheques: cobraba una comisión por cada cheque; prestaba dinero: a las tasas de interés de Colombia, mucho más elevadas que las francesas; arreglaba las gestiones del viaje para hacer venir a los familiares de los colombianos a Francia; y tenía un sistema de envío de remesas más barato que el ofrecido por el mercado.

Néstor, por su parte, lleva seis años en Francia. En situación legal desde el punto de vista del permiso de residencia, empleado en una cadena de alimentos, goza de una posición estable jurídica y económicamente. Ante sus compatriotas, él se presenta como "abogado". Últimamente, se ha dedicado a "ayudar a los migrantes": su trabajo consiste en explicarles a las personas que para regularizar su situación deben enviar cartas a las autoridades en Colombia. Néstor redacta esas cartas y cobra entre 30 y 50 euros por ese "trabajo".

Daniel y Néstor ofrecen una serie de "servicios" por los que cobran. Es posible que el primero no sepa que sus actividades son penalizadas por la ley en su país de residencia, en virtud de un conjunto de medidas severas contra la usura y el tráfico de seres humanos. Néstor, por su parte, es un migrante que capitaliza su formación escolar utilizando sus habilidades como escribano para asesorar a otros migrantes que no tienen esta capacidad. Su sistema de difusión de información es opaco. Por ejemplo, redacta cartas a personalidades y ministros que no existen en Colombia, o se inventa reglas migratorias que no existen en Francia.

Evidentemente, si Daniel y Néstor prosperan -ambos tienen su clientela- y gozan de reconocimiento por parte de un sector de los migrantes es porque sus acciones aparecen no sólo como normales, sino, incluso, como loables. Los usuarios han incorporado la idea de que las relaciones son, naturalmente, monetarias. Los individuos están dispuestos a pagar altas sumas con tal de conseguir sus objetivos.

Esta situación contrasta fuertemente con la manera de actuar de los militantes franceses, quienes ubicados en la esfera de la reivindicación motivan sus actos esencialmente bajo el imperativo del derecho. En las redes de apoyo a los migrantes prima la idea de que hay que defender y hacer respetar los "derechos fundamentales". Las asociaciones que trabajan por los "sin papeles” están formadas por personas que trabajan benévolamente, como sucede en este comité: 
En un suburbio de la región parisina, cada sábado por la mañana se reúnen los militantes del Comité ivryen de lutte contre la discrimination et le racisme. Casi todos estos militantes son profesionales, varios son jubilados. Todos se han ido formando en el derecho de extranjeros. Dos veces por semana prestan asesoría gratuita a los migrantes. Allí orientan a las personas, redactan cartas a las autoridades y comienzan a instruir los procesos judiciales, cuando hay caso. Uno de los mejores abogados especialistas en derecho de extranjeros de la región parisina brinda sus servicios gratuitos periódicamente a esta asociación. Elabora demandas y hace un seguimiento a casos individuales. Esta asociación no sólo brinda estos servicios de manera gratuita y desinteresada. Los militantes del comité también hacen acciones de cabildeo frente a los proyectos de ley: despliegan y firman comunicados, asisten a reuniones de redes antiexpulsión, promueven las manifestaciones y realizan marchas y manifestaciones ante las autoridades.

El trabajo de estos militantes se inscribe en el marco del asociacionismo francés, un vector muy importante de la vida social. De acuerdo con el Centro de estudios e investigación sobre la filantropía, hoy en día existen en ese país más de un millón de asociaciones, y se fundan unas 70.000 cada año -es difícil conocer su número exacto, pues muchas dejan de funcionar sin estar disueltas oficialmente-. En 2004 se estimaba que las asociaciones tenían más de once millones de voluntarios, y se calcula que una tercera parte de ellas hace un trabajo con contenido militante -son asociaciones humanitarias o de defensa de los derechos e intereses (Engels et al., 2006)-. Evidentemente, la idea de cobrar dinero por estos servicios se sale de los parámetros en los que se concibe la acción ${ }^{4}$.

4. El único rubro que suelen cobrar las asociaciones es la inscripción, una suma módica. La mayoría de las que trabajan a favor de los migrantes no exige afiliación previa a la asociación.

\section{La desconfianza ante la ley}

EN LA PERSPECTIVA DEL REBUSQUE, EL DERECHO O LA LEY PUEDEN SER VISTOS como un obstáculo que hay que superar. Ante las dificultades generadas por la esfera legal, surgen métodos para acortar el camino, como en el caso siguiente: 
Ovni tiene 44 años. Llegó hace tres años y medio. Está "medio resignado" a vivir sin papeles. "Si a los 50 años no me los han dado, me devuelvo". Pero no lo quiere hacer ahora por el honor, no quiere volver como alguien que fracasó. Hablando de los papeles, dice: "Estoy seguro de que pagando, se pueden obtener los papeles. Es difícil dar con la persona, porque los franceses se las dan de serios”.

Ovni no ha logrado encontrar la manera de dar la "mordida" para obtener sus papeles. En su concepto, es injusto que él no tenga papeles, y por eso le parece legítimo el camino de la "mordida". Pero también cuida que no se le malinterprete. Advierte: "Yo nunca he hecho un torcido, y eso que viví diez años en los Llanos, en plena bonanza coquera".

Sin embargo, ya ha interiorizado fuertemente la idea según la cual el universo de lo legal es otro campo de batalla. Hace un año se asoció con otros dos compatriotas para ayudar a los migrantes. Al cabo de un tiempo en el que habían trabajado a la manera de una red benévola e informal, sin estatutos, formaron una asociación. Convocaron a una reunión donde informaron que les darían "tarjetas de identidad" a los colombianos irregulares -una tarjeta plastificada con una fotografía y el nombre de la asociaciónpara que no los expulsaran. Esto es, una medida sui generis, sin fundamento legal alguno. Cuando confronto a Ovni sobre este punto me asegura que estoy equivocada, que esta tarjeta sí sirve para evitar expulsiones.

Por su parte, las personas que ya se han afiliado a la asociación y que han recibido los carnés me explican que aun cuando es posible que no les sirva para evitar ser expulsadas, tampoco les hace daño tenerlo. No se cuestionan sobre su utilidad real ni sobre su fundamento legal. En cambio, son categóricas en afirmar que es "positivo" que alguien haga algo "por la comunidad".

Para los individuos, la ley no es una fuente legítima de arbitraje, sino un artificio de la fuerza. De allí su desconfianza ante ella y su sentimiento de que la justicia es negociable. De la misma forma ocurre con Daniel, el caso que referí más arriba. Tras varios años de ejercer su práctica de "ayuda" a sus compatriotas, este hombre fue juzgado por "blanqueo", "ejercicio ilegal de la profesión de banquero" y "ayuda a la estadía irregular en banda organizada”, y condenado por las leyes francesas. Para las personas de su entorno se cometió una injusticia. La decisión de condenarlo parecía tanto más ilícita en tanto él "no le hacía 
mal a nadie”. Consideraban que Daniel era "muy dedicado" a las personas, pues los sacaba de apuros. "Entienda que yo sin poder cobrar mi cheque, estaba fregado. Daniel me ayudaba y era normal que cobrara”, me decía un obrero colombiano radicado en París.

Como muchos de sus compatriotas, esta persona ignoraba que incluso un indocumentado puede tener una cuenta bancaria en Francia. Evidentemente, hay corporaciones y bancos que abusan o incumplen la ley. Sin embargo, estas arbitrariedades pueden ser denunciadas y dan lugar a reparaciones. Varias asociaciones trabajan para hacer efectivos este tipo de derechos de los migrantes.

\section{La violencia como recurso}

UN COMPORTAMIENTO QUE VA UN PASO MÁS ALLÁ DE LA ACTITUD DUAL ANTE la ley, y que se entiende bastante bien a la luz del rebusque, es el recurso a la violencia. En un universo en donde los individuos no conciben el derecho todos los medios son válidos para resolver los conflictos. La violencia se vuelve un recurso, entre otros posibles, que se usará cuando fallen otras opciones, como el diálogo o la persuasión. Así sucedió en un caso que me fue referido y que expongo a continuación, aun cuando antes es necesario dar algunas pinceladas de contexto.

El medio de la construcción -o bâtiment- es aquél donde muchos hombres de la región andina encuentran su inserción laboral. Existe una amplia gama de trabajos relacionados con ella: desde la obra negra y la demolición hasta el trabajo artesanal -acabados, carpintería, vidrios- y la gestión administrativa -secretariado de la empresa, relación con los clientes, etcétera-. Según el nivel de calificación, la antigüedad y el manejo del francés, los individuos se acomodan en el espectro laboral. Sin embargo, en toda la rama está extendido el "trabajo al negro" . Las grandes constructoras subcontratan con empresas pequeñas para trabajos específicos -poner baldosas o tapetes, pintar-. Estas empresas son menos controladas y emplean

5. El trabajo ilegal o "trabajo al negro" es aquel que se realiza por fuera de la legislación laboral: cubre delitos como el préstamo de mano de obra, los empleos no declarados, el fraude al seguro de empleo, entre otros. Está muy difundido en sectores económicos como la construcción, la restauración, el cuidado de niños y ancianos, los servicios de limpieza y la hotelería, y no es realizado exclusivamente por los extranjeros. Según estadísticas de $2002,70 \%$ de los infractores eran franceses. 
una parte del personal legalmente, otra "al negro". Buscan mano de obra económica, flexible y relativamente calificada. Los colombianos suplen parte de esta demanda, aun cuando es un sector competido con migrantes de otras proveniencias.

En este medio escuché muchas quejas por parte de los trabajadores: por el mal trato, por los abusos en los horarios y, sobre todo, por la paga inferior a la establecida o el no pago. Pude verificar personalmente las prácticas abusivas de algunos patrones. En general, estos son migrantes con mayor antigüedad, que han logrado regularizar su situación y han amasado un pequeño capital; además, hablan francés, condición indispensable para inspirar confianza y negociar con los clientes. Los patrones negocian tarifas sumamente elevadas con sus clientes, pero la paga a los trabajadores no guarda proporción ni con los precios que cobran ni con las tarifas de la mano de obra en el mercado.

En cambio, las condiciones de trabajo son estrictas. Los obreros deben cumplir horarios desde muy temprano en la mañana, trabajar los sábados hasta horas de la noche y deben aceptar trabajos riesgosos. Víctor me cuenta la historia de un "patrón", colombiano, dueño de una empresa de construcción, que tiene la fama particular de ser "mala paga". "Yo prefiero no trabajar con él para evitarme problemas", me dice. Y me refiere lo que pasó hace un tiempo: como este patrón no le había pagado lo debido a un trabajador que le había hecho varias veces el reclamo de la deuda, el lesionado pagó a alguien para que le matara al hermano, en su ciudad natal, en Colombia. Y le advirtió: "Vaya ahorrando para la tumba de su mamá”. En respuesta el patrón pagó lo adeudado.

No pude ocultar mi estupor: -“iMatarlo? ¿Por qué no lo denunciaron?”. -“Es que denunciarlo no nos devuelve la plata”, respondió mi informante. La violencia física es considerada como un mecanismo expedito para resolver los conflictos, como un recurso legítimo en la medida en que revierte una situación injusta. Se sitúa por fuera del derecho, universo que se desconoce abiertamente. Recordemos que incluso en el marco del trabajo informal o trabajo "al negro" los trabajadores tienen derechos sociales. Asociaciones como el Gisti se dedican a dar a conocer los derechos que les asisten a los trabajadores extranjeros, y que en caso de abusos laborales los trabajadores pueden acudir a los prudhommes, es decir, a los jueces laborales. 


\section{La desconfianza institucional}

UNA DE LAS CONSECUENCIAS DEL REBUSQUE ES QUE LAS ACCIONES SE TRAducen en términos más desinstitucionalizados que la reivindicación. En un mundo donde el universo del derecho existe sólo en sordina, los individuos poco se inclinan a dirigirse hacia las instituciones, las organizaciones o lo que pueda representar la formalidad y la legalidad.

Esta "desconfianza institucional” ha sido documentada a escala latinoamericana. El politólogo Rafael Vázquez (2002) hace énfasis en la desconfianza hacia instituciones centrales de la democracia como el Congreso, el poder judicial, el ejército o la presidencia. A una escala más pequeña, he constatado esta desconfianza en el comportamiento cotidiano de los migrantes andinos en Francia.

Ya vimos cómo Raúl ignora prácticamente todos los pasos referidos al derecho, pese a su voluntad de obtener el asilo. Las figuras jurídicas o institucionales se refieren a conceptos vagos, y este caso no es una excepción. Entre los andinos y específicamente entre los colombianos hay una tendencia a no solicitar asilo, lo cual contrasta con la gran mayoría de los migrantes del tercer mundo que intentan ingresar a Francia: casi todos realizan el trámite del asilo; por ejemplo, ciudadanos de un país como Sri Lanka obtienen en un alto porcentaje el refugio ${ }^{6}$. El caso de Colombia es muy ilustrativo, sobre todo teniendo en cuenta que es uno de los pocos países de América que, por su situación de elevada violencia

6. No discutiremos acá sobre las motivaciones de quien solicita el asilo. Por medio de la evidencia empírica pude constatar que, proporcionalmente por comunidades, la colombiana lo solicita muy poco. A manera de contraste, mientras que en 2005 hubo 2.853 de Sri Lanka que pidieron el asilo -para una comunidad estimada en 50.000 habitantes-, sólo 80 colombianos hicieron la solicitud el mismo año - para una población estimada de 35.000 habitantes-. Para más detalles, se puede consultar el informe del Office français de protection des réfugiés et apatrides (Ofpra) (Oficina de refugio) de 2005 .

7. En toda Europa se han endurecido las condiciones para obtener asilo. En algunos países existen cuotas, y se ha generalizado la práctica de establecer listas de "países seguros": se niega así, de antemano, la posibilidad misma de solicitarlo. política y social, no ha sido incluido en la lista de "países seguros" de la Unión Europea, lo cual significa, concretamente, que existe una probabilidad más alta de que se les conceda el asilo ${ }^{7}$ a sus ciudadanos que a los migrantes de muchas otras nacionalidades. En este sentido, con respecto al comportamiento general de los migrantes, el de los colombianos es una excepción. 
He anotado también la ausencia de colombianos en los comités que trabajan por los "sin papeles" o por los derechos de los migrantes -como se aprecia en el gráfico 4-comportamiento atribuible al hecho de que bajo la lógica del rebusque el derecho no interviene como inspirador de la acción.

En las estrategias dictadas por el rebusque las personas tienen poca confianza en las instituciones. Esto se vio con la familia Pérez, acogida por un Comité de trabajo por los sin papeles de un barrio de París. Al inicio, como se dijo, los padres no entendían ese apoyo irrestricto no solicitado. A la socióloga, que además era compatriota y estaba "enterada" del asunto, le preguntaban: “¿Usted qué piensa? ¿Esto sí será bueno? ¿Será útil?”. A las personas del Comité les preguntaban: “¿Y usted por qué está haciendo esto?". Y se tomaron un tiempo antes de aceptar la respuesta que se les daba: "Porque usted lo necesita".

Así mismo interpreto la respuesta de Rodolfo, un colombiano que requiere ayuda para escribir unas cartas en francés e intentar regularizar su situación. Cuando le sugiero que contacte a determinadas asociaciones que podrían ayudarlo, se niega. Luego me dice que las asociaciones toman las coordenadas de las personas para hacerlas expulsar luego. Curiosamente, esta persona había obtenido trabajo gracias a una asociación. Cuando le pido detalles, es incapaz de recordarla: "Son unos viejitos del pueblo donde yo vivo. No sé cómo se llaman ni qué hacen”.

Comportamientos descritos más arriba, como el no acudir ante el prudhomme para mediar en los conflictos laborales o no asesorarse para abrir una cuenta bancaria, traducen una misma desconfianza institucional.

\section{Conclusión y PERspectivas}

C

ON EL CRUCE DE ESTOS DOS EJES, ACCIÓN COLECTIVA/ACCIÓN INDIVIDUAL, Y reivindicación/rebusque, obtenemos un nuevo filtro de análisis que les da relieve a las acciones observadas. Lo que antes se veía en balnco y negro aparece ahora con sus coloraciones y matices. Por las razones expuestas a lo largo de este artículo, pienso que la introducción de las estrategias es un aspecto central en la comprensión de la acción. 
Llegados a este punto, surgen algunos comentarios. El primero se deriva de las observaciones empíricas, de las que, como se vio, se evidencia una fuerte impronta de la estrategia del rebusque entre los migrantes colombianos. Estas evidencias ameritan ahondar en el plano explicativo -ia qué se debe la prevalencia del rebusque?- y exigen una confrontación en el empírico -¿observamos las mismas estrategias en otros entornos? ¿Es el rebusque una estrategia propia de determinados grupos?-.

Para profundizar en el nivel explicativo es necesario conceptualizar el rebusque. Esto es, considerar esta estrategia a la luz de las teorías de la acción. Evidentemente, este es un objetivo que desborda la intención de este artículo, que se dedicó a la presentación de la noción y su aprovechamiento como herramienta analítica para el estudio de comportamientos sociales observados entre los migrantes. Sin embargo, soy consciente de que es preciso considerar esta noción a la luz de un marco teórico comprehensivo.

Segundo, estas evidencias se deben enriquecer con más observaciones sobre el terreno. El campo de las migraciones ofrece un terreno privilegiado en cuanto pone de presente las diversas lógicas de extranjeros y nacionales, con sus formas contrastadas de acción. Las consideraciones desarrolladas en estas páginas sobre los migrantes colombianos permiten establecer un parangón con observaciones hechas en otros entornos, en otras geografías o en otros momentos históricos.

Por último, la perspectiva centrada en las estrategias que ejercen los individuos enriquece las miradas sobre el proceso de la integración. El enfoque que parte desde el migrante, que involucra el punto de vista del actor, permite ir más allá de los análisis que consideran el proceso de integración social desde el punto de vista de la sociedad de acogida.

\section{BIBLIOGRAFÍA}

Boudon, RAYMOND. 1997. “Le 'paradoxe du vote’ et la théorie de la rationalité: L'économie du politique”. Revue française de sociologie. 38 (2).

Bourdieu, Pierre. I984. "La grève et l'action politique”. En Questions de sociologie. Minuit. París. 
CENTRE D’ÉTUDE ET DE RECHERCHE SUR LA PHILANTHROPIE. "La France associative en mouvement”. Documento consultado en el sitio http://www. cerphi.org/pdf_communiques/France_associative_en_mouvementPresse.pdf el Io de octubre de 2006.

Cohen, James. 2005. Spanglish America. Éditions du Félin. París.

DewitTe, Philippe. I999. Immigration et intégration: l'état des savoirs. La Découverte. París.

DurkHeim, ÉmiLe. 1967. Les règles de la méthode sociologique. Les Presses universitaires de France. París.

El Ghozi, Laurent. I999. "Action en faveur de l'accès aux soins et de l'insertion des gens du voyage. L'expérience de l'ASAV à Nanterre”. Migrations Société. 63.

Engels, Xavier, Matthieu Hély, Aurèlie Peyrin y HélÈne Trouvé (comps.). 2006. De l'intérêt général à l'utilité sociale. La reconfiguration de l'action publique entre État, associations et participation citoyenne. L'Harmattan. París.

Étiemble, AngÉlina. 2002. "Les ressorts de la diaspora tamoule en France: associations, médias et politique”. Cahiers de Recherches de la MIRE. I3-I4.

Fahet, Georges, Françoise Cayla, Nadège Drouot, Nathalie Simmonot y Guillaume Fauvel. 2004. L'Observatoire de l'accès aux soins de la Mission France de Médecins du Monde. Rapport 2003. Orsmip, Toulouse; Médecins du Monde, París.

FASSIN, DidiER. 2002. "La discrimination en pratiques. Sources, processus, objets”. En Didier Fassin, Estelle Carde, Nathalie Ferré, Sandrine Musso-Dimitrijevic. "Un traitement inégal: les discriminations dans l'accès aux soins”. Migrations Études. Io6.

Fillieule, OliviER. I993. Lutter ensemble: les théories de l'action collective. L’Harmattan. París.

García Villegas, Mauricio. 2004. "No sólo de mercado vive la democracia: el fenómeno del (in)cumplimiento del derecho y su relación con el desarrollo, la justicia y la democracia”. Revista de economía institucional. 6 (IO).

GonzÁlez, Olga L. 2007. "Del exiliado al migrante económico: reconfiguración de la migración latinoamericana en Francia”. En David Khoudour (ed.). En busca de un nuevo El Dorado: análisis del fenómeno migratorio colombiano. Universidad Externado de Colombia. Bogotá.

. 2005. "Les droits sociaux à l'ère des migrants: la 'débrouille' des Latino-américains en France”. Migrations Société. IO2. 
LAMARA, FARID. I999. "L’accès aux soins et à la santé de populations roms/ tsiganes migrantes en situation de grande exclusion dans trois pays d'Europe: Espagne, France, Grèce. Étude qualitative, approche ethnosociologique”. Médecins du Monde. Juin.

Leuenberger, CÉLINE. 2004. "Les Soninké du foyer Pinel: lieux de vie et organisation”. Mémoire de maîtrise de sociologie urbaine. Université Paris X-Nanterre.

Marek, Anna. 2002. "La création du Gisti". Plein Droit. 53-54.

Mathieu, Lilian. 2004. Comment lutter? Sociologie et mouvements sociaux. Ed. Textuel. París.

Pardo, Patricia. I995. "Un réseau de peintres en bâtiment colombiens". Hommes et migrations. II87.

Percot, Marie, Andrea Tribess y Gérard Robuchon. i995. "Tamouls srilankais en France”. Migrations Études. 59.

REA, ALONDRA. 2005. "Naviguer entre deux rives. L'expérience des immigrants provenant de Santuario (Colombie) à Paris". Memoria de DEA. EHESS. París.

SimÉAnt, Johanna. I998. La cause des sans-papiers. Presses de SciencesPo. París.

VÁzquez García, Rafael. 2002. "El problema de la desconfianza institucional como freno a la gobernabilidad: América del Sur frente a las democracias occidentales". VII Congreso internacional del CLAD sobre la reforma del estado y de la administración pública. Lisboa. 8-II de octubre.

Volovitch-Tavares, Marie-Christine. I995. Portugais à Champigny: le temps des baraques. Ed. Autrement. París.

\section{Páginas web}

Réseau éducation sans frontières: http://www.educationsansfrontieres. org/

Organización Pajol, red de lucha por los derechos de los inmigrantes en Francia: http://pajol.eu.org/ 